\title{
Public perceptions of global warming: United States and international perspectives
}

\author{
Richard J. Bord ${ }^{1, *}$, Ann Fisher ${ }^{2}$, Robert E. O'C onnor ${ }^{3}$ \\ ${ }^{1}$ Department of Sociology, ${ }^{2}$ Department of A gricultural Economics and Rural Sociology, and ${ }^{3}$ Department of Political \\ Science, Pennsylvania State University, University Park, Pennsylvania 16802, USA
}

\begin{abstract}
National and international survey data on global warming are summarized in terms of levels of awareness, actual knowledge, degree of concern, perceived risk, and willingness to pay or sacrifice to mitigate or adapt to potential negative impacts. The data indicate the following: solid awareness of and support for general environmental goals; an awareness of and concern for global warming; a flawed understanding of global warming that is the result of an inappropriate application of a general pollution model; considerable perceived threat from global warming but less so than for most other issues; and a limited willingness to sacrifice to better cope with global warming. Although global warming generates concern around the globe, it is not a 'front-burner' issue. Concern tends to be highest in Canada, most of Europe and South America. Errors in assessing causes of global warming are global in nature. International data demonstrates considerable support for economic sacrifices to deal with environmental problems, including global warming. Our own data support but go beyond earlier data by implying that global warming is not a salient issue, and that people across the globe will support global climate change initiatives that do not levy unusual hardships; but they cannot be expected to voluntarily alter their lifestyles.
\end{abstract}

KEY WORDS: Attitudes · Global warming · Climate change

\section{INTRODUCTION}

Regular assessment of public attitudes on general environmental concern began, both in the United States and other countries, in the 1970s. These surveys demonstrate increasing public knowledge and concern (Dunlap \& Scarce 1991). Many social analysts argue that there has been a world-wide revolution in environmental awareness (Milbrath 1984, Dunlap \& Scarce 1991, Dunlap et al. 1993) to the degree that traditional ways of understanding the world have been replaced by a 'New Environmental Paradigm' (Dunlap $\&$ Van Liere 1978). Other analysts have been less effusive (Ladd \& Bowman 1995). Interest in and concern for the specific issue of global warming ('the greenhouse effect') is a relative latecomer as a survey topic. Surveys including global warming items surfaced in the early 1980s and full-blown interest emerged in the late 1980s and continues. Questions generally focus on

*E-mail: rjb7@psu.edu some or all of the following: levels of awareness, actual knowledge, degrees of concern, perceived risk, and willingness to pay or sacrifice to mitigate and adapt to potential negative impacts.

Improved understanding of public perceptions about global warming can contribute to informed scientific and policy discussions of climate change. Scientists need to know how the public is likely to respond to climate impacts or initiatives, because those responses can attenuate or amplify the impacts. Policy makers need to know what the public wants, in order to design policies that will be supported or at least tolerated. Both groups need to understand the extent to which people's responses will differ across regions.

This paper moves toward improved understanding by summarizing the empirical literature in each of these areas using both U.S. and international studies. This is not intended to be a comprehensive compilation of all studies done on global warming perceptions. Because the results of these studies are consistent, only the more prominent studies are noted. 
An enduring dilemma in survey research is how to interpret accurately the implications of the results. It is generally assumed that surveys overstate respondent concern (Sterngold et al. 1994) and that some topics generate 'socially desirable' responses (Kidder \& Campbell 1970). Environmental concern is a likely candidate for the exhibition of these problems. Few citizens in any country are likely to admit a lack of concern for environmental degradation, because this is akin to being ignorant and uncaring. Furthermore, the structure of most environmental surveys reinforces the perception that the environment is a serious issue and demands concern from any respectable citizen: surveys seldom put environmental concerns in the comparative context of other social and personal problems.

We will supplement our review of national and international surveys with data from our own national survey that address some of these issues. Our data put global warming attitudes and beliefs in the comparative context of other social and personal issues and obtain multiple measures of perceived risk. This should provide us with a better understanding of just how concerned people are and the specific dimensions of their concern.

\section{OUR DATA}

In spring and summer of 1997 we collected one of the most comprehensive databases on the U.S. public's beliefs, attitudes, and behavioral intentions about global warming. A mail survey of a random sample of residential addresses from the 48 contiguous states provided completed questionnaires from 1225 adults, a response rate of $59 \%$. In comparison with census population figures, our sample over-represents males $(62 \%)$ and persons 66 and older (24\%). Weighting procedures produced insignificant changes in the tables for this paper, so the results are not weighted.

Asked to participate in a study of public priorities for goals and issues affecting their communities, respondents answered 5 pages of questions about goals and comparative threat perceptions; 4 pages about climate change; 4 pages about their social and political values; and 2 pages of demographics. The purpose of our overall project is to develop and test a risk perception model for climate change.

In order to get the respondent thinking contextually, the first question asks for a rating of 11 goals. The following 7 questions ask for judgements about this list of issues (in the order presented): violent crime, hazardous chemical wastes, the disease AIDS, air pollution, cancer, global warming, heart disease, water pollution, and automobile accidents. This format provides the means to assess the relative standing of global warming in an array of other major social/environmental issues. The questions in this section relate to the relative importance of these issues, how informed people claim to be about them, and the extent to which they perceive each problem poses serious threats to their own health and well-being.

Then, 5 series of questions focus on global warming. Items measure respondents' scientific understanding, perceived personal and social threats, and judgements of the likelihood that they and others would take certain personal sacrifices to reduce the threat of global warming. Because our data set offers more complete and timely information on public attitudes than previous research, we use it to illustrate our general discussion of national and international perspectives.

\section{PUBLIC AWARENESS OF AND GENERAL CONCERN FOR GLOBAL WARMING}

Prior to the mid-1980s in the United States, public awareness of, and concern about, global warming was very limited. Cambridge polls for 1982, 1986, 1988, and 1989 demonstrate increasing concern and awareness, with the most noteworthy increase occurring between 1986 and 1988. In 1982, only $12 \%$ judged 'the greenhouse effect' as being 'very serious' while $36 \%$ selected the 'don't know' option. By 1988, 39\% chose 'very serious' and only 15\% selected 'don't know' (Dunlap \& Scarce 1991). Concern in the U.S. hovers around $47 \%$ and self-reports of awareness are quite high in recent surveys (Dunlap 1996).

1988 was a key year in the development of public concern for global warming in the United States. A severe drought and heat-wave coincided with J ames Hansen's 1988 testimony before Congress that global warming had begun. The public made the link, the media and environmental groups dramatized the correlation, and concern peaked in 1989 (Colglazier 1991). Ungar (1992), however, argues that the intensity of concern diminished in following years. Popular and scientific journals urged restraint, the uncertainty in climate change predictions was increasingly emphasized, and public interest faded with the onset of cooler, wetter summers.

While the sense of urgency visible in 1989 may have diminished, surveys indicate that public concern and awareness remains substantial in the U.S.: a 1996 survey by the Sustainable Energy Coalition indicates that $34 \%$ of Americans judge global climate change as 'very' serious and $37 \%$ choose 'somewhat' serious.

The survey picture in other countries parallels the U.S. experience but with variations. Studies done in 12 European countries in 1982 and 1986 on 'public concern over global environmental change' included 3 
dimensions of change: plant and animal species extinctions, depletion of world forest resources, and possible climate change from $\mathrm{CO}_{2}$ emissions (reported in Kasperson et al. 1990). On average, 34\% of these respondents indicated concern or worry over $\mathrm{CO}_{2}$ emissions in 1982 and 38\% concurred in 1986.

By 1992, citizen majorities in 13 of 24 countries picked 'very serious' as the option to describe the threat of global warming (Dunlap 1994). To put those figures in perspective, however, it must be noted that global warming received the fewest 'very serious' votes among a list of 7 environmental problems. The other problems and the number of countries expressing majority concern are: air pollution (20), water pollution (19), loss of rain forest (20), loss of ozone (19), loss of species (15), and contaminated soil (15). In these international surveys, the United States did not muster a majority expressing concern for global warming.

Our 1997 data puts the concern and awareness issues in a wider context. Table 1 presents the results of asking respondents to indicate the degree of importance of 11 personal, social, and environmental goals. Consistent with arguments made by Hamilton \& Wright (1986), personal goals (marriage, income) and social goals (crime reduction and improving schools) take precedence over other issues. In terms of statistically significant differences, pollution reduction and national park maintenance are part of a second tier of importance, along with reducing poverty. Reducing the federal deficit and maintaining a strong military comprise the third tier of importance. Alone at the bottom is slowing the rate of global warming.

An optimistic interpretation of this finding is to stress that $43 \%$ of the U.S. public thinks that slowing the rate of global warming is somewhat important. A pessimistic interpretation emphasizes its placement at the bottom of a list of issues. The pessimistic interpretation is buttressed by the fact that U.S. national surveys asking open-ended questions about 'what is most important to you' generally find fewer than $5 \%$ of respondents mentioning environmental issues with global warming totally absent (Hamilton \& Wright 1986, Dunlap \& Scarce 1991). The relatively low urgency of global warming compared to other personal, social, and environmental issues noted in both U.S. and international surveys urges caution in concluding that global warming is a 'front-burner' issue. Although large percentages of the public indicate some level of concern, they express greater concern for a host of other issues.

However, there can be little doubt that awareness of, and general concern for, global warming is almost universal. Concern tends to be highest in Canada, most of the European Countries, and South America (Dunlap 1994). Compared to these countries, concern in the United Sates is modest to low. Publicly acknowledged pronouncements about global warming began in 1957, reached the policy consideration stage in 1979, and resulted in a television production about 'The Climate Crisis' in 1983. Four years later U.S. Senate hearings and United Nations sponsored meetings began (Ungar 1992, p 488-489). By the time Hansen told Congress that global warming has begun, public opinion formation was well underway. Subsequent apparent increases in climate extremes continued to generate concern about global climate change. However, the intensity of concern over this issue tends to be significantly less than concerns for other personal, social, and environmental issues.

Table 1. Goals rated in terms of importance to respondent (in \%). (Original 7-point scale has been collapsed so that scale points 1, 2, and 3 are 'not important', 4 is 'midpoint', and 5, 6, and 7 are 'important'.) The exact wording of these and other questions can be obtained from any of the authors upon request

\begin{tabular}{|lcccc|}
\hline & Not important & Midpoint & Important & Missing \\
\hline Personal & & 5 & 78 & \\
Having a secure and loving marriage & 11 & 8 & 79 & 6 \\
Making enough money to live comfortably & 7 & 10 & 71 & 5 \\
Feeling wanted and needed by friends and family & 14 & 9 & 81 & 5 \\
Social & & 12 & 75 & 5 \\
Lowering the rate of violent crime in country & 5 & 15 & 62 & 5 \\
Improving our nation's schools & 8 & 17 & 56 & 7 \\
Reducing poverty and homelessness & 18 & 18 & 51 & 6 \\
Eliminating the federal budget deficit & 20 & & 69 & 6 \\
Maintaining a strong military & 25 & 14 & 61 & 7 \\
Environmental & 11 & 18 & $\mathbf{4 3}$ & $\mathbf{8}$ \\
Meducing air and water pollution & 15 & $\mathbf{1 9}$ & & \\
Slowing the rate of global warming & $\mathbf{3 0}$ & & & \\
\hline
\end{tabular}




\section{PUBLIC UNDERSTANDING OF GLOBAL WARMING}

Global warming has all the characteristics of issues that are difficult to understand. It is a complex issue characterized by substantial uncertainty (Halford \& Sheehan 1991, Levy-Leboyer \& Duran 1991, Kempton 1993, Berk \& Schulman 1995). The complexity and uncertainty even affect expert decision making (Nordhaus 1994). Global climate change is far removed from direct experience. Temperature and rainfall variations and weather extremes of various types can be experienced, global warming cannot. People's concept of global warming comes from a jumble of experiential data and from existing 'cultural' and 'mental' models (Kempton 1991, 1993, Bostrom et al. 1994, Kempton et al. 1995). What cultural models are accessed to provide guidance in understanding this issue?

The previously mentioned 'New Environmental Paradigm' encompasses a pollution model of environmental problems. Its elements include concern about contaminated air and water in terms of both health and ecosystem impacts, with an emphasis on hazardous chemical pollution, realization of dramatic species loss, awareness of population pressures, concern for dwindling natural areas and fear for future generations (Dunlap \& Scarce 1991).

The global nature of this pollution model is illustrated by the 'Health of the Planet' survey that demonstrates extensive environmental concern and support in 24 nations. Concern is not restricted to more affluent countries, as some social theorists have hypothesized. Dunlap \& Mertig (1995) conclude, 'Although the results vary considerably depending upon the measure, overall national affluence is more often negatively rather than positively related to citizen concern for environmental quality - contradicting conventional wisdom' ( $p$ 121). The greater concern among less affluent countries may reflect the reality of more serious environmental problems in those countries. Direct experience is a powerful shaper of attitudes (Fazio 1995).

Mertig \& Dunlap (1995) also found, in 17 countries, more overall support for environmental protection than for 'anti-nuclear power', nuclear disarmament, women's rights, human rights, and animal rights, although all of these achieved majority support in virtually all cases. Finally, large majorities (range $=64$ to $92 \%$ ) in 24 countries agreed that environmental problems will affect the health of their children and grandchildren over the next $25 \mathrm{yr}$.

That the pollution model guides perceptions of global warming is illustrated by an open-ended question, administered in 6 countries, asking for the causes of global warming. The top response, 'pollution', was mentioned by 28 to $41 \%$, depending on country of origin; the second largest response involved CFCs (chlorofluorocarbons) or ozone (4 to $37 \%$ ); then, 'fossil fuel use' (4 to $22 \%$ ). Other responses were at rates too low to be meaningful.

Kempton et al. (1995) argue that the pollution model is not entirely inaccurate as applied to global warming and may be valuable in the sense that it generates concern and support. They also note, however, that it leads to significant errors in judgment that could affect policy in important ways. For example, many people think that the installation of scrubbers in industry smokestacks reduces greenhouse gases; the opposite is true.

Interestingly, the inaccuracies in judgment engendered by applying the pollution model to global warming characterize judgments made in all countries surveyed. For example, majorities in 6 countries (Canada, U.S., Mexico, Brazil, Portugal, and Russia) recognized the contribution of auto exhaust emissions, rainforest depletion, and coal and oil emissions to global warming. Majorities, however, also inaccurately targeted aerosol sprays while some majorities and substantial minorities picked nuclear power plants and refrigerators and air conditioners. U.S. domestic surveys have found exactly the same pattern of results (Bostrom et al. 1994, Kempton et al. 1995, Bord et al. 1997). Widespread confusion between atmospheric ozone depletion and global warming is an important part of these misunderstandings.

Importantly, in 6 countries surveyed, people are aware that their understanding of this complex issue is incomplete and, perhaps, subject to error. Only 3 (Portugal) to $13 \%$ (Canada) reported that they understand this issue 'very well'. 'Fairly well' was selected by a low of $18 \%$ in Portugal and a high of $47 \%$ in Canada. Only the U.S. and Canada had a majority expressing some understanding of global warming.

Our 1997 national sample reflects knowledge and confusion levels similar to other surveys worldwide. Table 2 demonstrates both accurate and inaccurate judgments. The first 5 items are clearly causes of global warming. The others are either very minor causes or not causes at all. As noted in other surveys, there is confusion over the role of upper-atmospheric ozone depletion as an environmental threat. Apparently many people view the ozone hole and global warming as part of the same process. Surprisingly few respondents judge the heating and cooling of homes as a cause of global warming. Perhaps the source of temperature control in homes is not understood by many Americans. The application of a general pollution model is reflected in the substantial number of people who link aerosols and insecticides with global warming. Those who chose the generation of nuclear power 
Table 2. J udgments of whether the following are causes of global warming (in \%). The first 5 items form a scale with an 'alpha' coefficient of 0.74 , the last 4 with an 'alpha' of 0.64

\begin{tabular}{|lcccc|}
\hline & Not a cause & $\begin{array}{c}\text { Minor or } \\
\text { secondary cause }\end{array}$ & $\begin{array}{c}\text { Major or } \\
\text { primary cause }\end{array}$ \\
\hline Pollution/emissions from business/industry & 4 & 25 & 69 & M issing \\
Destruction of tropical forests & 9 & 25 & 64 & 2 \\
People driving their cars & 7 & 41 & 49 & 2 \\
Use of coal and oil by utilities & 10 & 42 & 13 & 3 \\
People heating and cooling their homes & 31 & 54 & 63 & 3 \\
Depletion of ozone - upper atmosphere & 10 & 25 & 25 & 3 \\
Use of chemicals to destroy insect pests & 20 & 50 & 21 & 3 \\
Use of aerosol spray cans & 14 & 58 & 3 \\
Nuclear power generation & 36 & & & 3 \\
\hline
\end{tabular}

Table 3. Answers to the question: How informed do you consider yourself on each of the following? (in \%). (Original 5-point scale has been collapsed so that scale points 1 and 2 indicate 'not informed', 3 is 'midpoint', and 4 and 5 are 'well informed')

\begin{tabular}{|lcccc|}
\hline & Not informed & Midpoint & Well informed & Missing \\
\hline Auto accidents & 14 & 34 & 50 & 2 \\
Crime & 5 & 45 & 48 & 2 \\
Heart disease & 11 & 32 & 52 & 2 \\
Cancer & 11 & 36 & 46 & 3 \\
The disease AIDS & 13 & 39 & 32 & 2 \\
Water pollution & 19 & 44 & 24 & 2 \\
Air pollution & 18 & 48 & $\mathbf{2 6}$ & $\mathbf{2}$ \\
Hazardous chemical wastes & 33 & 38 & & \\
Global warming & $\mathbf{3 4}$ & & & \\
\hline
\end{tabular}

as a minor or major cause of global warming are probably unfamiliar with this technology and may have been influenced by the large plumes of steam emitted by these facilities.

When put into a comparative context, judgments of personal informedness are noteworthy. Table 3 includes the distribution of responses to a question asking how informed the respondent feels he or she is on the 9 issues listed previously. Hazardous chemical wastes and global warming are virtually tied for last in this list. Although most Americans claim to be environmentalists, relatively few people think they are 'well informed' on any of the environmental issues. M ajorities or near-majorities, however, judge they are well informed about auto accidents, crime, heart disease, cancer, and AIDS. This may be because information about, and direct experience with, the social and health issues is much more pervasive than with the environmental issues.

This section has shown how a major cultural model, used to explain the revolution in world-views, has evolved a robust pollution model of perceptions that is applied somewhat indiscriminately to global warming. The global nature of this 'New Environmental Paradigm' is remarkable and is a testimony to the effective- ness of environmentalist groups around the world. The pollution model, however, induces significant errors in judgment when applied to global climate change. Whether these errors have any real implication for environmental policy decisions is a question for future research. The Kempton et al. (1995) study and our own (1997) data indicate that accurate understanding correlates significantly with support for initiatives to mitigate global climate change.

\section{PERCEIVED THREAT OF GLOBAL WARM ING}

It is one thing to express general concern over an issue but quite another to have fears relating to particular dimensions of that issue. The term 'threat' is used in this section rather than the over-used term 'risk'. No surveys actually measure perceived risk in the sense of dose level times the probability of being affected. The focus here is closer to what is meant by the term 'dread': a sense that something bad will happen that could have wide-ranging, very negative impacts (Slovic et al. 1979, M cDaniels et al. 1992).

In the United States, a series of Cambridge surveys have asked questions about 'the greenhouse effect' 
Table 4. J udgments of how likely the respondent is, during his or her lifetime, to experience serious threats from the following (in $\%$ ). (Original 5-point scale has been collapsed so that scale points 1 and 2 are 'not likely', 3 is 'midpoint', and 4 and 5 are 'likely')

\begin{tabular}{|lccrr|}
\hline & Not likely & Midpoint & Likely & Missing \\
\hline Auto accidents & 12 & 33 & 53 & 2 \\
Violent crime & 31 & 38 & 29 & 2 \\
Cancer & 11 & 35 & 51 & 3 \\
Heart disease & 15 & 31 & 9 & 38 \\
The disease AIDS & 74 & 15 & 32 & 3 \\
Air pollution & 26 & 33 & 23 & 3 \\
Water pollution & 28 & 37 & $\mathbf{2 2}$ & 3 \\
Hazardous chemical wastes & 42 & 32 & $\mathbf{4}$ & \\
Global warming (greenhouse effect) & $\mathbf{4 4}$ & & & \\
\hline
\end{tabular}

(Dunlap \& Scarce 1991). In 1982, 1986, 1988, and 1989, after providing an explanation of the greenhouse effect, respondents were asked to judge its degree of seriousness. The percentages choosing 'very serious' climbed from 12 and $24 \%$ the first 2 years to 39 and $41 \%$ the last 2 years. Separate polls in 1987 and 1989 asked a national sample about 'potential threats to the overall quality of the environment' and how much 'a problem threatens your personal health and safety' (Dunlap \& Scarce, 1991). Ten environmental problems were listed, ranging from air pollution to depletion of the ozone layer. 'The greenhouse effect' was sixth on the list. In 1987, 45\% responded that the greenhouse effect is a 'clear threat' to the environment and 37\% responded that it is a 'clear threat' to them personally. In 1989, those percentages increased significantly to 69 and 66, respectively. Similar results were found in 1984 and 1988 when respondents were asked how 'serious a problem your children or grandchildren will be facing 25 to 50 years from now' from 'the greenhouse effect': percentages choosing 'very serious' were 37 and 65 in those 2 years, respectively. Recall that 1988 was the banner year for raising global warming awareness in the United States.

More recent polls show similar results with perhaps some attenuation in perceived threat. In USA Today's 1992 national survey, $38 \%$ of the respondents said they did not know enough about global warming to form an opinion. Of those who reported an opinion, $63 \%$ view global warming as a 'major threat'. In 1996, The Sustainable Energy Coalition reported 34\% selecting 'very serious' for global climate change. In August 1995, the Wirthlin Group's national survey asked respondents to prioritize 13 environmental problems: global warming came in next to last. M ore central to the threat issue, when asked an open-ended question about the 'single most important problem facing the United States today' all environmental issues were eclipsed by social and pocketbook concerns. This issue of relative threat is discussed more below.
International surveys consistently demonstrate moderate to high perceived threat. Among the 24 countries comprising the 'Health of the Planet' survey (Dunlap et al. 1993), 13 countries have majorities choosing 'very serious' in response to global warming. Global warming, however, has the lowest percentage choosing 'very serious' relative to 6 other environmental problems. Countries not distinguished by majorities voting 'very serious' are the United States, 5 A sian countries, Finland, The Netherlands, Hungary, and Russia. The United States and the $5 \mathrm{~A}$ sian countries range between 36 and $47 \%$ choosing 'very serious'. Among the 6 countries (Canada, U.S., M exico, Brazil, Portugal, and Russia) responding to the long form of the 'Health of the Planet' survey (Dunlap 1996), all but Russia have majorities choosing the 'very harmful' option for global warming's impacts on agricultural production and survival of animal species. Interestingly, Canada and the United States have small minorities, 27 to $31 \%$, expecting harmful economic and living space choice impacts. In all 6 of these countries, except Russia, large majorities judge that global warming has already begun.

The surveys discussed above ask general questions of threat. They do not ask about specific threats to the respondent nor do they put the perceived threat of global warming into the context of perceived threats from other environmental and social problems. Our 1997 data accomplish both of these tasks and, so doing, shed further light on what 'concern' and perceived threat mean. Table 4 presents the results of judgments of how likely the respondent is, during his or her lifetime, to experience serious threats to health and wellbeing from the 9 issues appearing in Tables $2 \& 3$.

The relative rankings of these perceived risks closely mirror expert judgments of risk probability. Heart disease, cancer, and cars are the greatest killers. Although fear of crime and concern about AIDS are high, personal risk from these is low. Of the environmental risks, air pollution may well be the most severe threat to personal health. Again, global warming is 
Table 5. Judgments of how likely each of the following is, during the next $50 \mathrm{yr}$, given a $3^{\circ} \mathrm{F}\left(\sim 1.6^{\circ} \mathrm{C}\right)$ increase in temperature (in \%). (Original 5-point scale has been collapsed so that 1 and 2 are 'unlikely', 3 is 'midpoint', and 4 and 5 are 'likely')

\begin{tabular}{|c|c|c|c|c|}
\hline & Unlikely & Midpoint & Likely & Missing \\
\hline Many people's standard of living will decrease & 51 & 24 & 22 & 3 \\
\hline Starvation and food shortages in much of the world & 38 & 24 & 35 & 3 \\
\hline Rates of serious disease will increase & 38 & 25 & 35 & 3 \\
\hline Richer nations will have to donate money to poorer nations & 35 & 26 & 36 & 3 \\
\hline My standard of living will decrease & 59 & 20 & 17 & 4 \\
\hline There will be starvation and food shortages where I live & 68 & 18 & 11 & 3 \\
\hline My chances of serious illness will increase & 52 & 25 & 20 & 3 \\
\hline There will be few problems, people can adapt & 30 & 28 & 39 & 3 \\
\hline My area will experience better weather & 48 & 25 & 24 & 3 \\
\hline
\end{tabular}

lowest in perceived personal threat. Previous studies indicate that hazardous waste scores very high on the 'dread' dimension (Hadden 1991). In this study, however, hazardous waste and global warming are judged least likely to embody personal threats. Respondents apparently separate the societal and personal implications of environmental threats. Most other surveys' questions eliciting judgements of concern imply societal concern.

Table 5 presents judgements of specific global warming outcomes in terms of personal and global threats. One striking finding in this table is the degree to which negative outcomes for others are judged as more likely than negative outcomes for the respondent. This finding, and the finding discussed in the above paragraph, strongly imply that interpretations of survey data on degree of threat should carefully distinguish whether the question implied general or specific threats. The results are likely to be very different.

Consistent with other U.S. surveys on environmental concerns, respondents do not think that standards of living are likely to be negatively affected by global warming. This raises the disturbing possibility that support for environmental programs is somewhat contingent on the perception that these programs will not dip deeply into one's pocket. Although a majority of Americans say we should be spending more on environmental protection, available data cannot predict their response to this issue in the case of economic downturn.

Table 5 also indicates that few respondents expect negative outcomes from global warming. In fact, 24 to $39 \%$ think that positive outcomes are likely. General concern levels hovering in the $60 \%$ range must be contrasted to the relatively small number of people who see specific negative outcomes from global warming. General concern may reflect socially desirable responses and not real risk estimates.

People across the world indicate a substantial perceived threat from global warming although the degree varies somewhat; perceived threat is relatively low in the United States. The indicated degree of threat, however, must be put in context. In every survey examined, both for the United States and other countries, concern for and fear of global warming is less than for any other environmental issue included in the survey (except 'chlorine contamination' in the Wirthlin Group study). Furthermore, few people see specific negative outcomes from global warming as likely. Considering that a substantial percentage of people select 'serious' or its analogs for virtually any issue included on a survey, including air conditioning filters, global warming's relative standing must raise further questions about how deep public fears really go.

\section{WILLING NESS TO PAY/SACRIFICE}

U.S. surveys since 1973 have portrayed a public willing to spend more on environmental problems in general (Dunlap \& Scarce 1991). Recent polls that include global warming as a specific issue have continued to find majorities indicating a willingness to pay to reduce its impacts. For example, the 1992 USA Today poll found that, of the $62 \%$ who claimed to have formed an opinion on global warming, 58\% said they would support a treaty to stop global warming even if it harms the economy now. The same percentage would support such a treaty if it increases the cost of gasoline and electricity. A 1996 national election poll asked if we should spend 'less', 'the same amount', or 'more' on 7 environmental problems (Rosenstone et al. 1997). Global warming came in significantly last in terms of recommended spending: $50 \%$ chose 'less' or 'same amount' while only 33\% picked 'more'. In contrast, $65 \%$ chose 'more' for cleaning up 'hazardous or toxic waste' and $52 \%$ chose 'more' for 'managing natural resources that are important to our economy, such as timber and fisheries'. 
Table 6. Answers to the question of how likely it is that most A mericans would willingly do each of the following environmentally friendly behaviors (in \%). (Original 5-point scale has been collapsed so that scale points 1 and 2 indicate 'not likely', 3 is 'midpoint', and 4 and 5 indicate 'very likely')

\begin{tabular}{|lcccc|}
\hline & Not likely & Midpoint & Very likely & Missing \\
\hline Install more insulation and weatherize & 14 & 24 & 60 & 2 \\
Replace older appliances & 28 & 30 & 41 & 1 \\
Buy a fuel efficient car & 45 & 24 & 30 & 1 \\
Carpool and drive less & 49 & 29 & 21 & 1 \\
Use less air conditioning and heat & 59 & 25 & 15 & 1 \\
\hline
\end{tabular}

Table 7. Answers to the question how likely is it that you personally would do each of these (in \%). (Original 5-point scale has been collapsed so that scale points 1 and 2 indicate 'not likely', 3 is 'midpoint', and 4 and 5 are 'very likely')

\begin{tabular}{|lcccc|}
\hline & Not likely & Midpoint & Very likely & Missing \\
\hline Install more insulation and weatherize & 11 & 15 & 73 & 1 \\
Replace older appliances & 18 & 21 & 60 & 1 \\
Buy fuel efficient car & 21 & 16 & 62 & 1 \\
Carpool and drive less & 49 & 20 & 30 & 1 \\
Use less air conditioning and heat & 32 & 26 & 42 & 1 \\
\hline
\end{tabular}

International data also demonstrate considerable support for economic sacrifices to deal with environmental problems. Majorities in 21 of 24 nations chose environmental protection over economic growth and majorities in 17 of these nations expressed a willingness to pay higher prices for environmental protection (Dunlap \& Mertig 1995). Much of this support comes from countries characterized by low per-capita incomes. The support found in the U.S. for government support of an international agency devoted to solving global environmental problems is repeated for all 24 countries in the 'Health of the Planet' survey. Majorities range from 56 to $90 \%$ who advocated contributing money for this purpose.

We asked 2 questions that provide further insight into the willingness of Americans to engage in behavior that would dampen global warming impacts, but at economic and convenience costs. Table 6 presents answers to the question of how likely it is that 'most Americans' will engage in 5 environmentally friendly behaviors. Table 7 presents the same question with 'you personally' as the referent. It is possible that judgments of what 'most Americans' will do is closer to the truth than the more socially desirable implications of asking what 'you personally' will do. After all, is not each of us generally more caring and magnanimous than our less perfect brothers and sisters?

There is a strong, statistically significant, difference between Tables $6 \& 7$. Especially for issues that imply considerable cost and inconvenience (replacing older appliances, buying a fuel efficient car, and using less cooling and heating), 'we' are certainly on a more ele- vated moral plane than 'other people'. The noteworthy exception is car pooling and driving less. The essential role of the automobile in the modern world is reflected in the fact that respondents are not enthused about these possibilities and do not think anyone else is either.

In any case, the uncertainties inherent in asking people if they would engage in socially desirable behaviors is demonstrated by these patterns of results. It is quite possible that expressions of willingness to pay or sacrifice are at least moderately influenced by social desirability considerations. It is equally clear, from this data and related studies, that U.S. citizens are unlikely to respond to pleas to drive less without further motivation to do so.

Although surveys in the United States and other countries almost overwhelmingly indicate public willingness to pay and sacrifice for environmental goals, this support has limits. In Kempton et al.'s (1995) battery of 149 items administered to small samples of environmentalists, lay people, dry cleaners, and sawmill workers, many items indicated an across-theboard willingness to pay and sacrifice. Majorities of all groups indicated that 'Americans are going to have to drastically reduce their level of consumption over the next few years.' Similarly, majorities in all categories agreed that 'energy conservation means doing without some things that give us comfort and enjoyment.' On the other hand, items that include a requirement to curtail fuel consumption or restrict driving elicited support only from environmentalists. This defense of driving privileges was also found in the 'Global Warming Caused by the Greenhouse Effect' survey (Doble et al. 
1990) and our own data. Majorities of laypersons agreed that necessities, such as heat, cannot be sacrificed no matter what the environmental costs. Large majorities in all categories except 'Earth First' members agreed that ' $M y$ first duty is to feed my family. The environment and anything else has to come after that.' More ominously, majorities in all groups felt that 'A mericans are too spoiled to change their lifestyle.' Our data also hints of at least moderate social desirability biases in questions about willingness to pay or sacrifice.

\section{SUMMARY}

It can be concluded that the public, both in the United States and in other regions:

- displays solid environmental awareness and support for environmental goals at the general level;

- demonstrates a general awareness and concern for global warming;

- has a somewhat flawed understanding of global warming due to the application of a general pollution model;

- perceives substantial threat from global warming, but the threat levels tend to be significantly less than those from other environmental and social problems; and

- expresses a willingness to pay and to make sacrifices for coping more adequately with environmental problems in general and global warming specifically, but that willingness may be contingent and limited.

\section{WHAT DOES IT ALL MEAN}

For policy purposes, what people think is far less important than what they do. In practical terms, do people embrace the New Environmental Paradigm with an enthusiasm that allows prediction of significantly altered individual behavior? Using a modern colloquialism, are they 'walking the walk' or simply 'talking the talk'? In terms of global warming, an individual's policy decisions can take 2 basic forms:

- whether to support government initiatives to mitigate and ameliorate; and

- whether to alter one's own lifestyle so as to contribute less to greenhouse gases.

Our interpretation of existing data is that, all things being equal, a majority of the world's citizens in most countries will support national and international initiatives designed to cope with global warming as long as these initiatives do not demand a significant alteration of lifestyle. Our reason for this interpretation is the nature of the survey data itself.
Perhaps the most troubling aspect of all the survey data around the globe, as applied to global warming, is that when global warming questions are included in lists of other environmental and social problems, global warming tends to reflect the least concern and support relative to the other issues. Given the tendency for people to indicate concern and support for most issues presented in surveys, the relatively low standing of global warming raises questions about the depth, or salience, of these attitudes. Salient attitudes are more likely to direct behavior.

People in all countries appear to be assuming that environmental protection in general, and global warming specifically, will have no significant negative impact on their household's economy. But public reactions may be 'up for grabs' in the event of an economic downturn, the necessity to levy additional taxes, or governmental demands for substantial personal sacrifice.

The leap from questionnaire response to likely behavior in a given situation is problematic at best. There is no doubt that the public in the United States and most other countries are environmentally aware and concerned. Nor is there any doubt that this concern generalizes to specific environmental issues such as global warming. Although global warming is not well-understood, it is still likely that concern will translate into support for policy initiatives related to global climate change. Or, perhaps more accurately, into an absence of opposition to such initiatives. Even those general izations, however, may be contingent on global climate change initiatives not appearing to have much impact on individual life styles. The American public does not support initiatives that threaten car use or home heating and cooling options. Perhaps more importantly, research in developed countries indicates few people perceive that global climate change initiatives might have negative impacts on the economy. Whether changes in that perception would result in less support is open to conjecture and is fodder for future research.

In discussing a New York Times poll indicating robust support for environmental regulations and more spending, Ladd (1990, p 11-12) notes that the '...Times failed to report other data which make clear that this response must be understood not literally but as a symbolic commitment to a goal.' He goes on to discuss surveys showing that large majorities said 'no' to an added $\$ 200$ a year tax burden and to an added 25 cent a gallon gas tax. Ladd echoes our observation that Americans tend to express support for virtually any abstract problem presented to them in surveys: 'But all sorts of other poll data make clear that the above answers reflect a more general anxiety Americans seem always to feel about important institutions and values-including the environment, work, religion, 
and the family - than the literal judgment that things are sliding.' Richard Cohn, the vice president for Response Analysis, also echos our research findings and conclusions: few Americans think that environmental problems affect their own communities but are more likely to assume that problems are somewhere else and the responsibility to solve environmental problems is not part of the public's perception of its civic duty.' (Cohn 1991, p 1).

Our own research, and the patterns of most existing studies, indicate that global warming is not a salient problem for most Americans. Concern for global warming is greater in most other countries. That does not mean that survey answers are given in 'bad faith'. It simply means that in the complexities and uncertainties of daily life, global warming is far down on the list of things requiring attention. It is our judgment that, barring somewhat catastrophic social or economic dislocations, most people would support or acquiesce to policy initiatives that address global climate change. We see little evidence, however, that this issue will alter most individual choices. The very large share of U.S. vehicle sales accounted for by truck-like gas guzzlers, especially over the past $5 \mathrm{yr}$, has to give pause to those arguing that we are all environmentalists.

Acknowledgements. We gratefully acknowledge financial support from the National Science Foundation (Grant SRB9409548) and Penn State's College of Agricultural Sciences (Intercollege Grant 3262) The views expressed are the authors' and should not be attributed to their employer or funding sources. We appreciate the thoughtful comments on an earlier draft from 3 reviewers and journal editor Brent Yarnal; the manuscript has been improved by their input.

\section{LITERATURE CITED}

Berk RA, Schulman D (1995) Public perceptions of global warming. Clim Change 29:1-33

Bord RJ, Fisher A, O'Connor RE (1997) Is accurate understanding of global warming necessary to promote willingness to sacrifice? Risk Health Safety Environ 339:339-354

Bostrom A, Granger Morgan M, Fischhoff B, Read D (1994) What do people know about global climate change? I. Mental Models. Risk Anal 14:959-970

Cohn R (1991) Why most A mericans still do not take responsibility for solving environmental problems. Response Anal No. $59, \mathrm{p} 1$

Colglazier EW (1991) Scientific uncertainties, public policy, and global warming: How sure is sure enough? Policy Stud J 19:61-72

Doble J, Richardson A, Danks A (1990) Volume III: Global warming caused by the greenhouse effect. Science and the Public: A Report In Three Volumes. The Public Agenda Foundation, New York

Dunlap RE (1994) International attitudes towards environment and development. Green Globe Yearbook, Oxford University Press, New York

Dunlap RE (1996) Public perceptions of global warming: a cross-national comparison. Human Dimensions of Global Environmental Change Programme, Report No. 8, Global
Change, Local Challenge, Geneva

Dunlap RE, Gallup GH J r, Gallup AM (1993) Health of the planet. George H. Gallup International Institute, Princeton, NJ

Dunlap RE, Mertig AG (1995) Global concern for the environment: is affluence a prerequisite? J Soc Iss 51:121-137

Dunlap RE, Scarce R (1991) The polls-poll trends: environment problems and protection. Pub Opin Q 55:651-672

Dunlap RE, Van Liere KD (1978) The 'new environmental paradigm.' J Environ Educ 9:10-19

Fazio RH (1995) Attitudes as object-evaluation associations: determinants, consequences, and correlates of attitude accessibility. In: Petty RE, Krosnick JA (eds) Attitude strength: antecedents and consequences. Hillsdale, Erlbaum, NJ

Hadden SG (1991) Public perception of hazardous waste. Risk Anal 11:47-57

Halford GS, Sheehan PW (1991) Human response to environmental changes. Int J Psychol 26:599-611

Hamilton RF, Wright J D (1986) The state of the masses. Aldine Publishing Co, New York

Kasperson R, Emani S, Perkins B (1990) Global environmental change, the media, and the public: preliminary data and observations. Sustainable development, science, and policy. Norwegian Research Council for Science and the Humanities, Oslo

Kempton W (1991) Public understanding of global warming. Soc Nat Resour 4:331-345

Kempton W (1993) Will public environmental concern lead to action on global warming? Annu Rev Energy Environ 18: 217-245

Kempton W, Boster J S, Hartley J A (1995) Environmental values in American culture. The MIT Press, Cambridge, MA

Kidder LH, Campbell DT (1970) The indirect testing of social attitudes. In: Summers GF (ed) Attitude measurement. Rand McNally, Chicago, p 333-385

Ladd EC (1990) What do Americans really think about the environment? The Public Perspective, May/J une, p 11- 13

Ladd EC, Bowman KH (1995) Attitudes toward the environment. The AEI Press, Washington, DC

Levy-Leboyer C, Duran Y (1991) Global change: new challenges for psychology. Inter J ourn of Psychol 26:575-583

M cDaniels TL, Kamlet MS, Fisher GW (1992) Risk perception and the value of safety. Risk Anal 12:495-503

Mertig AG, Dunlap RE (1995) Public approval of environmental protection and other new social movement goals in Western Europe and the United States. J Pub Opin Res 7:145-156

Milbrath LW (1984) Environmentalists: vanguard for a new society. State University of New York Press, Albany

Nordhaus WD (1994) Expert opinion on climate change. Am Sci 82:45-51

Rosenstone SJ, Kinder DP, Miller WE (1997) American national election study. Inter-university Consortium for Political and Social Research, Ann Arbor, MI

Slovic P, Fischhoff B, Lichtenstein S (1979) Rating the risks. Environment 21:14-39

Sterngold A, Warland RH, Herrman RA (1994) Do surveys overstate public concerns? Pub Opin Q 58:255-263

Sustainable Energy Coalition (1996) America peaks out on energy: A survey of 1996 post-election views. Sustainable Energy Coalition, Tacoma Park

The Wirthlin Report (1995) Research supplement. The Wirthlin Group, McLean, VA

Ungar S (1992) The rise and (relative) decline of global warming as a social problem. Soc Q 33:483-501

USA Today (1992) Environment: a look at issues surrounding the Rio Summit. USA Today Poll, Arlington, VA 